\title{
Correction to: The effects of Environmental Kuznets Curve toward environmental pollution, energy consumption on sustainable economic growth through moderate role of technological innovation
}

\author{
Zhaomin Zhang ${ }^{1} \cdot$ Taqadus Bashir $^{2} \cdot$ Jiaxuan Song $^{3} \cdot$ Shahab Aziz $^{2} \cdot$ Ghulam Yahya Khan $^{4} \cdot$ Sana Bashir $^{5} \cdot$ Aysha Zamir $^{6}$
}

Published online: 10 November 2021

○) Springer-Verlag GmbH Germany, part of Springer Nature 2021

Correction to: Environmental Science and Pollution Research (2021) 28:14115-14120 https://doi.org/10.1007/s11356-021-16956-y

The correct spelling of the $2^{\text {nd }}$ Author given name and the correct institution of the $5^{\text {th }}$ Author is presented in this paper.

Publisher's note Springer Nature remains neutral with regard to jurisdictional claims in published maps and institutional affiliations.

The original article can be found online at https://doi.org/10.1007/ s11356-021-16956-y.

Jiaxuan Song

Songjx87@163.com

Zhaomin Zhang

zhzhmin@szpt.edu.cn

Taqadus Bashir

doc.tbc.tabs@gmail.com

Shahab Aziz

Shahabaziz7@hotmail.com

Ghulam Yahya Khan

yqureshi79@gmail.com

Sana Bashir

sanabashir@ndu.edu.pk

Aysha Zamir

ayshaaer011@gmail.com
1 Department of Management, Shenzhen Polytechnic University, Shenzhen, China

2 Department of Management Sciences, Bahria University, Islamabad, Pakistan

3 Department of Economics and Trade, Qingdao City University, China, Qingdao, China

4 Kashmir Institute of Economics, University of Azad Jammu and Kashmir, Muzaffarabad, Pakistan

5 Department of Governance and Public Policy, National Defence University Islamabad, Pakistan, National Defence University Islamabad, Pakistan, Islamabad, Pakistan

6 Applied Economics Research Centre (AERC), University of Karachi, Karachi, Pakistan 